\title{
A Study of Gan Po Region Farming Customs from Dialect Special Vocabulary
}

\author{
Xiao Jiugen, Liao Lihong \\ Research Center of Language and language Life, Jiangxi Normal University, Nanchang, China
}

Email address:

jxsdxjg666666@sina.com (Xiao Jiugen),752350198@qq.com (Liao Lihong)

\section{To cite this article:}

Xiao Jiugen, Liao Lihong. A Study of Gan Po Region Farming Customs from Dialect Special Vocabulary. Science Innovation. Vol. 7, No. 5, 2019, pp. 143-148. doi: 10.11648/j.si.20190705.12

Received: November 14, 2019; Accepted: December 4, 2019; Published: December 9, 2019

\begin{abstract}
The gan po region, one of the earliest rice growing places in the world, has started the history of farming in ancient times. And, through archaeological sampling and excavation, wild rice and cultivated rice, 17,000 years ago and 12000 years ago, respectively, have been found by Chinese and American experts in Wannian district of Jiangxi province at the end of last century. It shows that the poyang area of Jiangxi province has become the beginning of rice farming in China early in the late paleolithic and early neolithic period, also, played an vital role in the history of rice farming in the world. The long history of agricultural civilization forms the folk culture of poyang farming, which is fully reflected in dialect vocabulary. Its folk customs reflected in the dialect vocabulary are mainly reflected in these aspects of spring plowing and sowing, rice field management, rice harvest, farmers' sacrifice and agricultural festivals and so on.
\end{abstract}

Keywords: Gan Po Region, Dialect Vocabulary, Farming Customs, Cultural Phenomenon

\section{从方言特殊语汇看赣鄱农耕民俗文化事象}

肖九根, 廖丽红

江西师范大学语言与语言生活中心, 南昌, 中国

邮箱

jxsdxjg666666@sina.com（肖九根）,752350198@qq.com（廖丽红）

摘要：远古时代, 赣鄱地区就已开始了农耕历史, 是现今所知的世界上年代最早的稻作发源地之一。上世纪末，中美 专家联合在赣省万年境内进行考古取样与挖掘, 发现了 17000 年前的野生稻和 12000 年前的栽培稻。它表明, 早在旧石 器晚期和新石器早期, 赣鄱地区就已成为中国稻作农业的开端, 而且在世界稻作史上也具有不可忽视的地位和作用。 悠久的农耕文明史形成了赣鄱农耕民俗文化, 这在方言语汇中得到了充分的反映。其方言语汇反映的民俗事象, 集中 地体现在春耕播种、稻田管理、稻禾收获、农家祭祀以及农事节日等方面。

关键词：赣鄱地区，方言语汇，农耕民俗，文化事象

\section{1. 引言}

赣鄱地区农耕文化已有万余年的历史，素有“鱼米之 乡”的美称。《史记·货殖列传》记载: “衡山、九江、江 南、豫章、长江, 是南楚也......楚越之地, 地广人希 (稀),
饭稻美鱼, 或火耕而水㱹。”上古时期, 濒临于长江之滨 的赣鄱地区曾属于楚越之地, 其时先民无疑已经过上了 “饭稻美鱼”的富足生活。文献记载, 赣鄱地区从石质农具 到青铜农具在历史上完成得很早, 其后便是铁质农具的更 
换与改进, 从而使农业生产得到了快速的发展。[1]（第 332-333页)

上世纪末，中美农业考古专家联合考察赣鄱万年境内 的仙人洞和吊桶环遗址, 通过出土稻的狍粉与植硅石分 析, 发现了距今一万七千年至一万二千年的野生稻和栽培 稻, 这不单是上世纪中国农耕考古的一大发现, 还是世界 稻作史上的一大奇迹。[2]此外, 在赣鄱地区的鄱阳、修水、 奉新、高安、南昌、清江、临川等地, 考古专家还发现了 新石器至商周时期的文化遗址, 也有栽培稻的遗迹及收割 工具。事实业已证明, 远古时代赣鄱地区就在这块神秘的 红土地上开始了农业耕作, 而且还是中国乃至世界栽培稻 最早的发源地之一。所以, 赣鄱人自豪而又自信地说, 赣 鄱农业不仅在中国甚至在世界稻作文化史上均写下了辉 煌的篇章。赣鄱人的这份自信既源自于充分的 “文化自 知”，也源自于内省的“自知之明”。[3]

悠久的农耕稻作史孕育着赣鄱地区深遂厚重的农耕 民俗文化，这在赣鄱方言语汇中得到了充分的反映。其方 言语汇所反映的民俗文化事象, 集中地表现在春耕播种、 稻田管理、稻禾收获、农家祭祀以及农事节日等方面。

\section{2. 春耕播种的方言语汇反映了赣鄱农耕民俗文 化事象}

赣鄱地区, 春耕播种等活动是一年农事中的头等大 事, 每项农事活动都打上了特定地域的民俗印迹, 也自然 而然地产生了独特的方言语汇。通过那些方言语汇, 人们 不仅可以了解赣鄱地区的农耕民俗事象, 还能领略其特定 的民俗文化景观。

\section{1. 方言语汇所反映的春耕农事习俗}

“春耕”活动, 赣鄱乡民一般是依据一年四季节气变化 进行的。他们所从事的农耕活动, 一般谓之“作田”或“整 田”。如春分节后, 乡民开始耕耙稻田, 方言俗称“整地”, 播种前整理秧田称为“整秧田”。稻田翻整后, 需借助“铙” 这种农具平整, 俗称“锤田”; 耕耙田后, 还需整平田面、 敲碎泥土、摚匀肥料, 乡民谓之“撰田”或“耖田”; 栽禾前, 需用耥耙推平地, 这道工序唤作“耥田”或“耥地”; 种作物 前, 要耕耘板结的泥土或土块, 这称之为“耕甲”。[4]《天 工开物》还记载了一种浆田或低洼田 (即“土性带冷浆 者”), 需要两道工序——“扎田” ( 又称“转田”) 和“徜田”, 但干田则需要四道工序, 即“犁田”“耙田”“扎田”“倘田”。

\section{2. 方言语汇所反映的播种农事习俗}

“播种”是农业生产中一项十分重要的工作，俗语说 “春种一粒粟, 秋收万颗子”, 它关系到这年能否获得丰收, 所以乡民都很重视这一工作。播种前, 先要用单犁将稻田 耙平, 灌水寸深, 乡民称其为“头犁头耙”; 接着, 便将稻 田搁置数天, 让其深埋于田泥里的禾秸、杂草发酵腐烂, 这就是所谓的“后田”; 之后, 再将稻田耙细耙平, 便可准 备播种、插种了。

播种, 赣鄱地区一般在清明前, 经过“选种”“浸种”“撒 谷”等工序来培育秩苗。其说法因地域不同而有所不同,
如有的地方将“选种”称作“下种”、“撒谷”称为“下秧”等。 选种是一项很重要的工作, 能否夺取粮食丰收, 此是关键 的因素之一。这正如乡民们所说的“种田选好种，不怕风 雨虫”, “好种出好苗, 好苗结好粮”。[5] (第88页) 至于“浸 种”, 明·宋应星《天工开物》提到“打包浸种”法。其法是: “先以稻麦稿包浸数日, 俟其生芽, 撒于田中。”也就是, 先将稻草铺于谷箩中, 再把稻种放入扎好, 在水中浸两至 三天, 提起放在墙边避风处, 用草盖住发热。过数天又置 于水中浸湿, 反复数次即能发芽, 前后约需十天左右。直 到今天, 许多地方浸种仍用此法。

关于浸种、播种等农活, 赣鄱地区还流传着不少农谚, 如樟树“懵里懜懂, 清明下种”, 吉安“懵懵懂懂, 清明浸 种”，上饶“二月清明不要慌，三月清明早下秩”，上高“二 月清明箩里青, 三月清明田里青”, 七阳“清明浸完种, 立 夏下完禾”, 赣东地区“寒潮头浸种, 寒潮尾撒谷”，赣西 地区“寒潮期间选种浸种, 寒潮过后抢晴播种”。这表明, 早稻下种时间一般在清明时节, 清明前后就要做好“包禾 种”“撒禾种”的系列工作。

\section{3. 方言语汇所反映的移栽农事习俗}

“移栽”是播种阶段最后一道工序, 一般在谷雨时节进 行，有的地方俗称“苻田”或“栽禾”。唐・白居易《孟夏思渭 村旧居寄舍弟》中就有“泥种水畦稻, 灰种香田粟”诗句, 这说明育秧移栽法历来都是赣鄱稻作农事中的一种习俗。

移栽是农家最忙的季节, 乡民将之形容为“背晒日头 肚遮荫”的四体落地农活, 最为辛苦繁重。开始移栽, 先 由师傅下田插下第一株秧苗, 俗云“牵莳”或“牵边”; 然后, 其他人随即跟上, 谓之 “跟莳”。如今, 移栽要求合理密植, 每步七行, 有的地方先“莳”框架, 俗称“打格子”, 目的是 使稻苗能茁壮生长。赣鄱奉新地区, 因为冷浆稻田多, 秧 苗移栽历来使用“骨灰酸秩根”法。

至于种苗何时移栽, 赣鄱各地也有农浐。例如, 靖安 “清明播种, 谷雨插秩”, 宜春“谷雨栽早禾, 节气正相当”, 丰城“农民不得闲, 谷雨沤完田”。还有如安义“清明浸种, 谷雨分秧”, 都昌“清明浸早种, 谷雨撒迟秩”, 等等。

\section{3. 稻田管理的方言语汇反映了赣鄱农耕民俗事 象}

耕作技术与田间管理方式, 是决定农业生产效益的另 一关键因素。不论耕作技术还是田间管理, 其方式的不同 所取得的效益也是不同的, 这在赣鄱地区方言语汇中也有 所反映。

\section{1. 方言语汇所反映的耕作技术方式}

自古以来, 赣鄱地区有刀耕火种、火耕水耨及深耕细 作几种技术。所谓刀耕火种, 就是烧草木灰作肥料挖坑下 种的一种耕作技术。这种方式直至今天, 赣鄱大部分农村 还在沿用, 农浐“有钱难买火烧土”就是这方面耕作经验的 总结。上世纪中叶, 赣北赣中农村有种红花草的习俗, 待 到春耕时再将红花草翻耕至深泥下, 使之沤烂作上好的肥 料, 乡民常说: “早禾好唔 (不) 好, 要看红花草。”[6](第 
53页)诚然, 如要将耕作方式划分历史阶段的话, 可以这 样说, 秦汉之前赣鄱地区基本上采用刀耕火种的耕作技 术; 秦汉以后, 据文献记载, 江南的耕作方式已经采用了 火耕水耨技术。一言以蔽之, 此时铁犁牛耕技术也已盛行 了。[7](第111-114页)实际上, 早在商周时期, 赣鄱地区就 已采用养牛与犁耕方法了。其时, 北方流行“二牛抬杜”式, 但那种耕作方式不适合赣鄱地区的实际, 所以牛耕技术直 到秦汉时期才得以推广。秦汉至六朝, 赣鄱地区实行的是 “一人一牛”犁耙方式, 与北方的耕作方式是不同的。所谓 深耕细作法, 南宋著名理学家陆九渊在教育弟子“论及士 人专事速化不根之文”弊病时便以此为喻, 不仅深刻阐释 了此法要义, 还将其上升为理论, 赋予普遍意义。他说: “吾家治田, 每用长大翼头, 两次锄至二尺许, 深一尺半 许外, 方容积一头。久旱时, 田肉深, 独得不旱。以他处 禾穗数之, 每穗谷多不过八、九十粒, 少者三、五十粒而 已。以此中禾穗数之, 每穗少者尚百二十粒, 多者至二百 余粒。每一亩所收, 比他处一亩不旁数倍, 盖深耕易蓐之 法如此。凡事独不然乎, 时因论及士人专事速化不根之文, 故及之。”[8](第191页)如果不取喻义, 仅以其法专论, 显 而易见，这一耕作技术对于推动农业生产、提高稻粮产量 是有重要意义的。

\section{2. 方言语汇所反映的稻田除草方式}

移栽之后, 第一要务就是田间管理了。俗话说得好: “三分在种, 七分在管”, “田里多管, 仓里谷满”。[5](第 92页)而稻田管理的第一项工作, 就是要为禾苗除草, 即 所谓“庄稼无巧, 勤除杂草”说的也是这个道理。晋・陶渊 明《归去来兮辞》诗云“或植杖而耘耕”，最先出现“足芸 (耘) ”法。其后, 宋·曾安止《禾谱》对之作了详细阐述: “足芸, 为木杖如拐子, 两手倚以用力, 以趾塌拔泥上草 秽, 隹之苗根之下, 则泥沃而苗兴, 其功与芸爪相类, 亦 各从其便也。”《天工开物》也论及到稻的“耗”法, 其俗 名为“挞禾”, 至今稻农还会用此农耕法。

赣鄱地区, 乡民把“除草”称作“耘禾”。一季稻要耘三 次禾, 这样既能松土, 又可除草。一般情况下, 禾苗长至 一尺余时䎣一次, 然后每隔半月后再耘一次。耘禾是人工 活, 以手或脚耘, 但大多以脚耘为主。脚耘时, 两脚跟上 各套一只以稻草自制的䈐, 俗称“耘禾脚塞”。不论哪种耘 法, 都是将草拔起后埋入泥中, 让其腐烂, 化为肥料。

\section{3. 方言语汇所反映的灌水施肥方式}

田间管理中, 少不了要给水稻引水、施肥、灭虫等, 赣鄱乡民想出了许多办法, 如乡村遍布水塘, 为农耕储水。 水塘内一般设有标界石, 俗称“塘注”。还有的乡村于稻田 间开沟挖渠, 一到灌水期, 只需将稻的田埂铲个缺口, 水 便能泪泪地流入, 亩亩相连, 每亩都可得到灌溉。

有一种田间管理叫“针水法”。据赣鄱东乡区的“针水 法”所示，在“投种”（一种播种方式，指播种过程中通过 两次投种, 最大限度地降低投种高度, 并通过相对运动使 种子落地时绝对速度为零) 之后, 放掉田里的水, 晒上三 日, 使田泥龟裂成纹后, 再引水回槽一次, 稻芽即可返青, 长势极好。
赣南地区至今还有一种“黄豆施肥法”一一撒黄豆于 稻田作肥料, 这有助于贫㾑稻田的改良。这一技术早在明 代就已实施过。《天工开物》云: “豆贱之时, 撒黄豆于 田，一粒烂土方三寸，得谷之息倍焉。”农浐亦云：“一粒 烂土方三寸, 三粒黄豆肥一兒。”利用人畜粪便、油榨枯 饼（如花生枯饼、芝麻枯饼、油菜籽枯饼等）、草根树皮 等作肥料, 对于改良稻田也有很好的效果。

此外, 赣鄱地区还流行着有关田管方面的农浐, 这都 是乡民生产经验的总结。例如, 萍乡有“禾打苞, 水撑腰 (禾孕穗时需要大量水, 否则影响幼穗分菜, 减少产量)”, 临川“早禾白一撒, 迟稻难估价 (如不预防病虫侵害, 不 仅早稻会受灾, 就是晚稻也会受到损失) ”, 新建“秋分禾 奔出, 霜降禾奔黄 (“奔出”即出穗, “奔黄”指成熟) ”。这 就是说, 无论稻禾的孕穗期还是成熟期, 都不能放松田间 管理工作。

\section{4. 农业祭祀的方言语汇反映了赣鄱农耕民俗事 象}

赣橎地区稻禾耕作的自然环境与气候条件, 有时会给 农业生产带来一定的损失。在此情况下，乡民往往祭祀天 地诸神, 祈求五谷丰登、消灾降福, 因而形成和传承了许 多有关农耕生产信仰与祭祀方面的习俗。当然, 农耕祭祀 主要是祭“社稷神”, 以求菩萨保佑。例如, 安福称“社稷 神”为“禾官”, 萍乡称“婆官”, 赣州称“土地神”或“社官”。

\section{1. 方言语汇所反映的社稷神祭祀习俗}

乡民祭祀社稷神方面的仪式活动较多, 此举数例以观 其俗。例如:

赣鄱地区一般于禾下泥之日, 乡民们就聚餐庆贺, 祭 社稷神。修水边陲重镇渣津镇乡民称之“唤土地”, 而三都 镇乡民则谓之“唤青”。在赣州、瑞金等地, 播种后第三天 为“禾子三朝”日, 乡民们要为之插香压纸钱, 还要摆祭神 米果等贡品。此外, 还有不少忌言讳语, 如禁大声说话, 管花生为“班芝麻”, 玉米为“辘轴仔”, 红薯为“抬藤仔”等。

赣中吉水乡村, 立春时要举行“扬神”仪式。各村设坛 请神, 用花炮把画有龙船的图腾从江边或小溪畔接来, 置 于祠堂门口之上, 以祈五谷丰登。闹神高潮过后, 各户端 来四碟素菜, 全村男丁围在八仙桌旁, 以手抓菜喝酒, 俗 称“喫菜酒”。[9]（第20-21页）

春社, “社”所指社官、社公, 是传说中的社稷之神, 有人说就是后稷, 为管理谷物生长的土地神, 俗称“福主”。 旧时, 乡民常于立春后戊申日（即第五个戊日）祭祀, 敬 祈“福主”保佑一方风调雨顺、人畜平安。[9]（第54页）

上元茧卜，“茧卜”这一祭祀活动即为正月上元日夜 晚, 乡人磨米粉浆, 其汤俗称皮, 将其切成细丝, 写某句 古语置于其丝上, 占卜一年的祸福。

春社, 唐・王贺《社日》这首诗就是赣东北铅山乡民 庆“春社”景象的真实写照。诗云: “我湖山下稻梁肥, 豚 栅鸡栖半掩扉。桑柘影斜春社散, 家家扶得醉人归。”春 社日, 乡人呼朋唤友, 举酒欢庆, 豪饮放歌。其间, 有人 载酒吟联, 谓之“开社”; 有人培土奠祖, 称之“蘸社”; 有 
人祈“福主”祭“社神”, 俗言“社祭”。贑鄱有些地方称“春社” 为“起社”或“做社”。

新春里, 赣鄱地区有迎春接福的习俗。例如, 吉水等 地称之为“接春”, 兴国叫“交春”。有些地方还有“打春送 春”“打春牛”之类的习俗。这些习俗, 表达了赣鄱乡民期 盼丰收的美好愿望。据了解, 粤西南江流域也流行类似于 赣鄱祭稻神、“舞春牛”之类的农耕习俗。[10]

\section{2. 方言语汇所反映的耕种祭祀习俗}

新春首次用牛耕田, 乡民称之“开犁”, 也常称之为“发 始”“起春”或“牛出行”等语。民国《万载县志》载: 灯节后, 香烛花爆择吉日犁田, 名“起春”。清・同治年间《万安县 志》载: 正月二十日, 俗谓之“天娏地西”, 佣工者是日上 工, 畜子牛者是日犁田。分宜习俗为农人初四犁田, 俗曰 “发试”又名“起春”。浮梁等地, 与“开犁”相似的习俗称之 “役牛”（俗称“使牛”），而赣州等地则俗称“起牛工”，这 些皆谓新年第一次驾牛开犁。

瑞金乡村, 人们将一把浸泡的稻种撒到种田里, 俗称 “禾子下泥”。到了第三天, 还要为撒到种田里的稻种做“禾 子三朝”呢。

古人云: “甲不开仓, 财物耗完; 乙不栽植, 千株不良。” 想必这是赣鄱乡民遵循的古训吧。在祭土地神后十天左右, 乡民开始浸稻播种, 认为祭拜了土地神, 谷禾发芽就会正常, 生长才茂盛。乡民将浸种俗称为“种子落缸”; 在其上往往放 张红纸、一把镰刀, 名其曰“催芽”, 并以之镇邪。

播种之后, 就是种谷生长的“返青”期了。赣鄱乡民举 行隆重的“开种门”仪式, 大多设酒、焚香、唱赞, 以昭示 农耕开始, 并将开始下田拔秩之日称作“开种门”, 临川等 地叫“春插”，樟树将“开秧门”的过程谓之“起种”。与之对 应的, 有“关秧门”仪式。据考察, 鄂东地区也存有这一农 耕习俗。[11]

“开秧门”仪式举行过后, 乡民便“插秩”了。武宁称之“种 禾”, 清•乾隆年间《武宁县志》载: “农民种禾, 联里为伍, 最相狎。”在赣州请人“插种”, 需备酒肉款待客人, 俗称“莳 田酒”。“苻田”能手第一个下田, 称之“牵莳”, 旧称“扯示”。 “莳田”过程中, 前者被后者超越了, 称之“笼住”; 居中但 慢于两侧者, 则称之“背门框”; “莳田”居后者, 称之“关进 猪仔笼”, 如南丰。“莳田”行距为两头尖中间鼓者, 称之“牛 卵禾”; 一头大一头小者, 称之“棺材禾”。遇此情况, “莳 田”者则要视情况添减禾苗, 人们称之“打岔行”。插秧技艺 还有“黄牛挨身”“单线穿针”“猴子弄棍”等称谓。“苻田”时请 帮工, 瑞金称之为“打伴”。为帮工奉送餐菜茶饭, 都昌谓 之“送点心”, 靖安谓之“过昼”或“打点”。[4]《修水县志》 还记载了一些乡村举行插秧比赛的盛况, 胜者尊为“栽禾 手”，输者贬为“拖倒筒”或“穿背心”, 繁是热闹有趣。

《临川县志》记载, “春插”时每天上午十点左右, 主 妇要送糯米团、米酒等食物至田间, 以供“栽禾客”享用, 此谓之“打娐狗”。

“种禾”前后，赣鄱地区会进行如“春鼓”“禾鼓”“田 鼓”“耘鼓”等活动, 以鼓励乡人种禾劳作。武宁将“种禾” 的“打鼓歌”称为“禾鼓”, “耘禾”的“打鼓歌”称为“耘禾鼓”, 管锄山或挖地的“打鼓歌”称为“锄山鼓”。

\section{3. 方言语汇所反映的秧稻管理祭祀习俗}

旧时, 上饶等地有“安苗”的习俗, 将艾叶果送至秧田 边, 以祈“社神”护种。新余等地, 有“燃天蚁”的习俗以求 秩田无害虫。

赣鄱都昌地区, 乡人遇早年, 相互架水车灌溉农田, 俗称之“大漭水”。歌源乡民以前每遇秋旱, 水稻病虫害严 重, 无力抗灾, 就举行迎神接仙的求雨灭虫活动。每当此 时, 家家户户洗净家具, 禁屠食素, 请道土到深山岩洞(俗 称“龙洞”或“龙井”)取清泉(俗称“仙水”), 或访名山寺庙迎 菩萨(俗称“神仙”)。当“仙水”或“菩萨”迎来时, 户户摆香 案, 男丁捧香盘, 一班人马敲锣打鼓, 燃放鞭炮, 举“长 枪”, 演“地戏”, 游行迎接。赣鄱乡村还有“祭神求雨”“求 龙降雨”等习俗。

赣州端午时节, 乡民在田地插红纸条竹片以求神灵灭 虫, 俗称“散禾花纸”，竹片则称“禾花竹”。

还有些地方以寻神灵帮助, 驱除自然灾害, 有所谓的 “打香火龙”习俗。[7]惊搵时“炒虫”，四月八“送毛娘子”, 这都是向神灵祈祷灭虫防灾的活动仪式。

瑞金乡村, 如遇虫害, 则有游神的习俗。乡人抬出仙 太娘娘(俗称“禾苗仙”)的金身，巡游房屋周围以及田间地 段, 美其名为“让仙太察看虫情”。

为了驱除农作物病虫害, 祈祷丰收, 过去瑞昌村民多 在稻禾抽穗时请道士念经做法事, 俗谓“倠苗”。县城东北 山区一带农户，旧时还习惯于每年中元节到田间焚香烧 纸, 并供献灰汁馃, 谓之“保苗”或“安苗”, 以祈神灵保丰 收, 田鼠不咬青苗, 野猪不毁庄稼。

\section{4. 方言语汇所反映的秋收祭祀习俗}

上世纪初中叶, 赣鄱地区重视早、中季稻, 较少有晚 季稻, 故其祭祀活动或习俗虽有一些, 但为数不多。例如:

待稻谷快要成熟时, 乡人在“割禾”前后要举行一些祭 祀活动, 这一习俗谓之“秋社”。

乡民收割前有“开镰”仪式，即“吃新日”（农历六月第 一个卵日) 举行“尝新”或“食新”活动。这天, 主人会邀请 村民来品尝第一次下地所割稻谷做出来的美食。

秋收后, 乡民一般有欢庆丰收的活动, 俗称“洗禾镰” 或“洗禾桶”。如南康“四月插禾毕, 邻里欢聚饮酒, 谓之“脱 秧根”; 及获毕又如之, 谓之“洗禾镰”。”有些地方还请帮 工来“吃酒（喝酒）”, 俗称“圆禾酒”或“做禾了”, 临川称 作“卖散”。赣州地区, 收割后乡人堆稻草, 也要打麻糍粑 果吃, 俗谓之“做满仓”。

晚稻收割后, 乡人要在当年冬天把土地翻整一遍, 俗 称“犁禾稿”或“倒稿”。赣鄱俗浐云“隔年不倒稿, 禾苗长不 好”, “隔年倒稿, 顶过捡窑”, 这还是有科学依据的。

\section{5. 农耕作物的方言语汇反映了赣鄱农耕民俗事 象}

赣鄱农耕历史悠久绵长, 其农耕作物也丰富多样。从 其所具共性看, 赣鄱农耕作物主要分为三类: 粮食作物类、 经济作物类和其他作物类。粮食作物类有: 水稻(早、中、 晚)、大麦、小麦、红薯、玉米(包栗)、小粟(狗尾粟)、大 
粟(高梁栗)、养麦(花麦)、芋头、早大豆、晚大豆、芒种 豆、豇豆、绿豆、蚕豆、踠豆、马铃薯等。经济作物类有: 甘蔗、烟叶、棉花、茶、黄麻、黑麻、梨瓜、香瓜、西瓜、 拦麻、席草、棕莲子、油菜、芝麻、花生以及药材如紫苏、 荆芥、白䓎、白非、枳壳、黄栃子、黄拍、杜仲、厚朴、 车前等。其他作物类有: 蔬菜如青菜、白菜、芥菜、辣椒、 大蒜、萝卜、番茄、韭黄、冬瓜、南瓜、丝瓜、黄瓜、凉 薯、菠菜、芹菜、莴苣、苋菜、豆角、田藕、生菜、香苾 以及作绿肥用的, 如紫方菜、肥田夢卜、细绿萍等。

粮食作物以水稻为主, 分为粳稻和籼稻。赣鄱地区万 年仙人洞遗址发现的野生稻 (17000年前) 和之后的栽培 稻（12000年前）都是粳稻, 赣江岸边新干界埠乡袁家村 发掘的两座春秋战国时的粮仓遗址, 其米粒也属粳米; 而 南昌南郊出土的东汉墓葬中的粳稻和籼稻, 则是这方面的 标本。宋・曾安止《禾谱》所载赣鄱地区所种稻种就达五、 六十种之多。这表明, 还在宋代赣鄱地区的农耕经济已经 得到了飞速发展。到了明清时期, 《天工开物》所载赣鄱 地区稻种, 高达 90 余种, 如早稻 28 种, 中稻 26 种, 晚稻 5 种, 糯稻 28 种, 旱谷 3 种。早稻约七十天即可收获, 粳稻 有“救公饥”“喉下急”之誉，糯稻的“金包银”“香稻”等品种 也享有盛名。有的品种称名有明确的地名标记, 如“云南 早”“湖广糯”“陕西糯”“池州占”“淮禾”等, 显然那属于引进 稻种。

《天工开物》还将水稻分为不粘者与粘者两类: “不 粘者, 禾曰秔, 米曰粳; 粘者, 禾曰稌, 米曰糯 (俗名“敂 源光”之类）。”本属粳稻但晚熟而带粘性的米, 称之“婑源 光”, 它不能用来酿酒, 仅可煮粥。以稻谷外形命名的, 长芒稻称“汶阳早”, 短芒稻叫“吉安早”。此外, 地方志也 记载了许多稻品名, 如明・正德年间的《袁州府志》卷二 《土产》载: “占谷, 以得种于占城而名, 红白两种, 有 五十日占, 名救公饥。熟最早; 有六十日占, 有八十日占、 百日占, 又有大占、须占、赣州旱、团谷旱; 糯谷, 稻之 黏者即秫, 可为酒, 制酿饵闻用之, 早糯以七月熟, 晚糯 以十月熟, 晚糯为佳, 其名有白壳糯、矮脚糯、鸭婆糯、 重阳糯、子江糯。”清・同治年间的《建昌府志》卷一《地 理志・风俗》载: “早稻春种夏收, 晚稻夏种秋末收, 早稻 获后再下秧, 十月收, 谓之两番。谷差小而力薄, 腉日多 有之。其类有五十日占、六十日占、八十日占、百日占、 白沙占、大谷占、细谷占、救公饥、粳米、青丝粳。糯, 稻之粘者, 一名秫, 可为酒, 其类有重阳糯、清流糯、老 人糯、红壳糯、石册糯、五十日糯、三友糯、光头糯。” 近代, 赣鄱地区还引进了早熟高产稻籼谷, 如“二夏白”“三 百穗”“宁都稻”“广东迟”等品种。而而洪涝的“铁脚撑”“八 月白”“晚白”“迟红”等晚稻种, 皆为晚清时期引进的。 [12][第128页]

东汉晚期, 赣鄱地区单一的稻种结构就开始有了变 化。汉桓帝时, “陈蕃尝为豫章太守, 以礼请 (徐稚) 署 功曹。稚为之起, 既谒而退, 蕃馈之粟, 受而分诸邻里。” 这说明至少在汉代就已经有了粟米。六朝时期, 赣鄱境内 已广泛种植水稻、麦、粟、菽、桑、麻等粮食与经济作物 了。南朝政府曾多次诏令各州郡长管督种, 至迟晋代, 粟 已成为赣鄱地区重要粮食品种之一。
南宋时，小麦已在赣鄱流域大面积种植，这在杨万里 的《过杨村》、《过南荡》和陆游的《小慗前平院戏书触 目》等诗中都有所反映。如《小慜前平院戏书触目》诗云: “稻积正青白鹭下, 桑椹烂紫黄鹏鸣。村虚卖茶已成市, 林薄打麦惟闻声。泥行扶犁叱新犊, 野饁烧笋炊香粳。” 说明其时赣鄱流域早已种植桑树、茶树, 并使用了铁犁牛 耕的农作方法。宋代已种植了粟米、黄豆、棉花等作物, 明清时期如赣南种植了烟草、蓝靛、甘蔗等作物, 同时还 引进了玉米、番薯、土豆等品种。另外, 九江县神墩商周 遗址中还出土过炭化的菱角、葫芦等作物。

\section{6. 农事节日的方言语汇反映了赣鄱农耕民俗事 象}

赣鄱地区，有关农事节日也有一些特殊的方言语汇， 这在一定程度上也反映出地域农耕民俗文化特色。例如,

每年农历“六月六”，古代称之为“天贶节”。这本是皇 帝晒龙袍的吉日，但民间传说它是土地菩萨的生日。赣鄱 铜鼓乡人, 这天定会把酒了猪血的花纸夹在小竹片上, 然 后插到田头, 祭祀土神, 此也称为“婆官烛”。[9](第54页) 农历夏至后的第三个庚日, 大约六月初八这天，乡人 称之为“分龙日”。这天, 因为要水溉田, 农家禁忌骂街或 挑便桶等, 以免冲撞龙王, 断了雨脚。久而久之, 这便成 了乡人日常农事活动中的一个节日。[9](第55页)

农历七月第一个卯日，正处于小暑与大暑之间，赣鄱 各地乡人举行丰收庆祝活动, 他们选取田间新谷, 煮成新 米饭, 合家享用, 这就是俗称的“喫新节”。不过, 由于地 域不同，其做法也略有不同。

秋收之后, 大约十月初一或十五, 赣鄱地区有些地方, 打麻糍, 炸大薯, 做油馃, 以这些美食表达庆丰收的喜悦 心情, 这就是乡人们所说的“十月朝”节日。

这些农事节日所产生的民俗文化，表达了赣鄱乡人庆 贺丰收、希冀幸福生活的快乐心情和美好愿望。

\section{7. 结语}

有人说，中国“具有五千多年农耕文明史”。[13]实际 上, 从考古发掘的文物看, 中华民族的先民们在万多年前 就开始了农业耕作, 创造了农耕文明。仅以赣鄱地区而言, 就有十分悠久的农耕史。从赣鄱境内考古发现的野生稻和 栽培稻来看, 专家们认为这不仅是人类最早食用野生稻的 证据, 而且还是目前世界范围内已知最早的人工栽培稻起 源的证据。也就是说, 赣鄱地区的人工植稻农业至少在新 石器时代就已经开始了。这也说明, 赣鄱农耕稻作史在中 国乃至世界农业发展史上都具有十分重要的地位和作用。

悠久的农耕历史，必然会产生深厚的农耕民俗文化; 而深厚的农耕民俗文化, 又是由其特定地域的农耕民俗事 象所决定的。因此, 赣鄱地区那深厚农耕民俗文化的形成, 也正是由其古老而独具特色的地域农耕民俗事象所决定 的。

一般而言，任何语言都是一定文化的载体，而一定文 化又是语言承载的内容, 二者相辅相成, 密不可分。不可 
否认, 特定的方言语汇与特定的民俗文化之间的关系, 也 不会例外。这正如有的学者所说的, 语言中民俗语汇的出 现, 既表现了语言的发展变化, 又反映了社会民俗的丰富 多彩。[14](第12页)正因为这样, 赣鄱地域诸如稻作播种、 稻田管理、稻禾收割、农家祭祀及农节喜庆等丰富多彩的 农耕方言语汇, 毫无疑问是其地农耕民俗文化事象的本能 反映。

所以说, 赣鄱地区悠久的农耕文明史, 产生了其独具 特色的农耕民俗文化, 而其独具特色的农耕民俗文化又使 大量反映农耕民俗事象方面的方言语汇最终得以形成, 它 们之间始终处于一个相互影响、相互渗透、相互依存的发 展变化之中。

\section{致谢}

基金项目: 国家社科基金重大项目（编号: 18ZDA297) ; 江西省社科联规划重点项目（编号: 13YY01)。

\section{参考文献}

[1] 李国强, 傅伯言.赣文化通志[M].南昌: 江西教育出版社, 2004。

[2] 史史如生.世界上最早的水稻种植出现的中国距今已有万 年之久 $[R]$.新浪网视频, 2018-11-08。
[3] 赵永帅, 秦龙.人类命运共同体的文化自知、文化自信与文 化自为 $[\mathrm{J}]$.江西师范大学学报(哲社科版), 2019（01）。

[4] 肖萍.江西吴城方言农业词汇例释[J].农业考古,2008(03)。

[5]《江西农浐》编辑部.江西农谚[M].南昌: 江西人民出版 社,1982。

[6] 张芳霖, 郑克强. 赣文化通典 民俗卷(上) [M].南昌: 江西人 民出版社,2013。

[7] 钟起煌.江西通史 秦汉卷[M].南昌: 江西人民出版社,2008。

[8] 钟起煌.江西通史 南宋卷[M].南昌: 江西人民出版社,2008。

[9] 余悦.江西民俗[M].兰州: 甘肃人民出版社2004。

[10] 郭永青.南江流域传统民俗歌舞的农耕文化因素及其传承 研究 [J].佳木斯大学社会科学学报,2018(05)。

[11] 孙军, 许春妮.传统农耕器具中的设计审美及其民俗文化表 现 [J].艺术教育,2019(05)。

[12] 黄志繁, 杨福林, 李爱兵.赣文化通典 宋明经济卷[M].南昌: 江西人民出版社,2013。

[13] 孙其勇.论农耕民俗文化在社会主义核心价值观中的时代 价值[J].吉林教育学院学报, 2017（01）。

[14] 曲彦斌.民俗语言学[M].沈阳：辽宁教育出版社,1989。 